\title{
Differential effects of metacontrast on target brightness and clarity
}

\author{
STEPHEN R. STOBER, EDWARD M. BRUSSELL, and MELVIN K. KOMODA \\ Concordia University, Montréal, Quebéc H3G IM8, Canada
}

\begin{abstract}
Magnitude estimates of target brightness and clarity were obtained in a metacontrast paradigm as a function of stimulus onset asynchrony (SOA), target and mask duration, and fixation location. Under conditions of backward masking, effects on brightness and clarity were in opposite directions at short SOAs (i.e., judgments reflecting less clarity were accompanied by judgments that indicated increases in target brightness). However, at long SOAs and under conditions of forward masking, estimates of target brightness and clarity moved in the same direction. The results are discussed in the context of the "sustained-transient" theories of visual masking, and it is concluded that, in their present forms, these theories cannot completely handle the data we have reported.
\end{abstract}

The phenomenon of metacontrast has been of interest for many years. It refers to the masking of a briefly presented visual target by a subsequently presented nonspatially overlapping mask. Many measures have been used to assess the magnitude of metacontrast as a function of numerous experimental manipulations. Some of the more common measures include brightness matches to a standard (Alpern, 1953; Matteson, 1969), luminance thresholds (Alpern, 1965; Alpern \& Rushton, 1965), duration thresholds (Fehrer, 1966; Kolers, 1962), target identification (Stewart \& Purcell, 1970; Weisstein \& Haber, 1965), and magnitude estimates of target completeness (Growney, 1976; Weisstein, 1971).

With few exceptions (e.g., Kolers, 1962), investigators in this area seem to share an implicit assumption that underlies all of these measures: To the extent that metacontrast has an effect on more than one perceptual dimension, the effects on the different dimensions are positively correlated. As an example, the effects of metacontrast on target brightness and clarity should always be in the same direction.

In the experiment reported below, we explored the validity of this assumption by taking simultaneous measures of the effect of metacontrast on both target brightness and clarity. The results suggest that there are conditions under which metacontrast effects on the two perceptual dimensions can be negatively correlated.

This research was supported by operating grants from the Natural Sciences and Engineering Research Council of Canada (Grant A9937 to Edward M. Brussell and Grant A0678 to Melvin K. Komoda) and by a fellowship from the Quebec Ministry of Education to Stephen R. Stober. This manuscript is based on two papers delivered at the annual meeting of the Canadian Psychological Association, Ottawa, Ontario, June 7, 1978. Requests for reprints should be addressed to E. Brussell, Department of Psychology, Sir George Williams Campus, Concordia University, 1455 de Maisonneuve Blvd. West, Montreal, Quebec H3G 1M8, Canada.

\section{METHOD}

Subjects

Two well trained, paid observers with normal visual acuity (Keystone Visual Skills tests) participated in the experiment. Each observer was naive to the purpose of the experiment.

\section{Stimuli and Apparatus}

The observers were presented with a 1-deg circular target that was adjacent to an annular mask whose width was $30 \mathrm{~min}$. In order to avoid problems associated with spatially aligning the target and mask, we modified one channel of a Scientific Prototype tachistoscope (Model GB) in the following way. A piece of Plexiglas with a hole cut in its center was attached to the end of one channel. Surrounding the hole was a ring (mask) cut from a piece of Munsell N9.5 paper. The annular mask was front illuminated. Mounted on the Plexiglas, immediately behind the hole, was a small mirror that was at a 45-deg angle to the glass. The mirror served to reflect diffused light from a Scientific Prototype rear illuminator through the hole, and hence provided control over the luminance level of the target disk. Light that was reflected from the front of the glass in the region beyond the annulus was determined to be minimal and, at worst, constant across all conditions.

The luminance of the target was $20 \mathrm{~cd} / \mathrm{m}^{2}$; for the mask, it was $30 \mathrm{~cd} / \mathrm{m}^{2}$, and for the black fixation field (that contained two red points between which fixation was maintained), it was $.1 \mathrm{~cd} / \mathrm{m}^{2}$. All luminance levels were measured with a Spectra Spotmeter (Photo Research, Hollywood). The target and mask durations were always equal and set at either 8 or $40 \mathrm{msec}$. The center of the target was presented either foveally or $1 \mathrm{deg}$ into the periphery.

\section{Procedure}

After $10 \mathrm{~min}$ of dark adaptation, observers were asked to estimate the magnitude of target brightness and clarity (i.e., edge definition and circularity) with respect to a standard stimulus. The standard was a second presentation of the target that occurred $500 \mathrm{msec}$ after the offset of the mask in a backward-masking condition, or $500 \mathrm{msec}$ after the offset of the target in a forward-masking condition. The brightness and clarity of the standard was defined by the number 10 . Numbers less than 10 meant that the target was less bright or less clear than the standard. Observers were required to give two numbers on each trial: one for brightness and one for clarity. Given perceptual variations from trial to trial, even under the same 


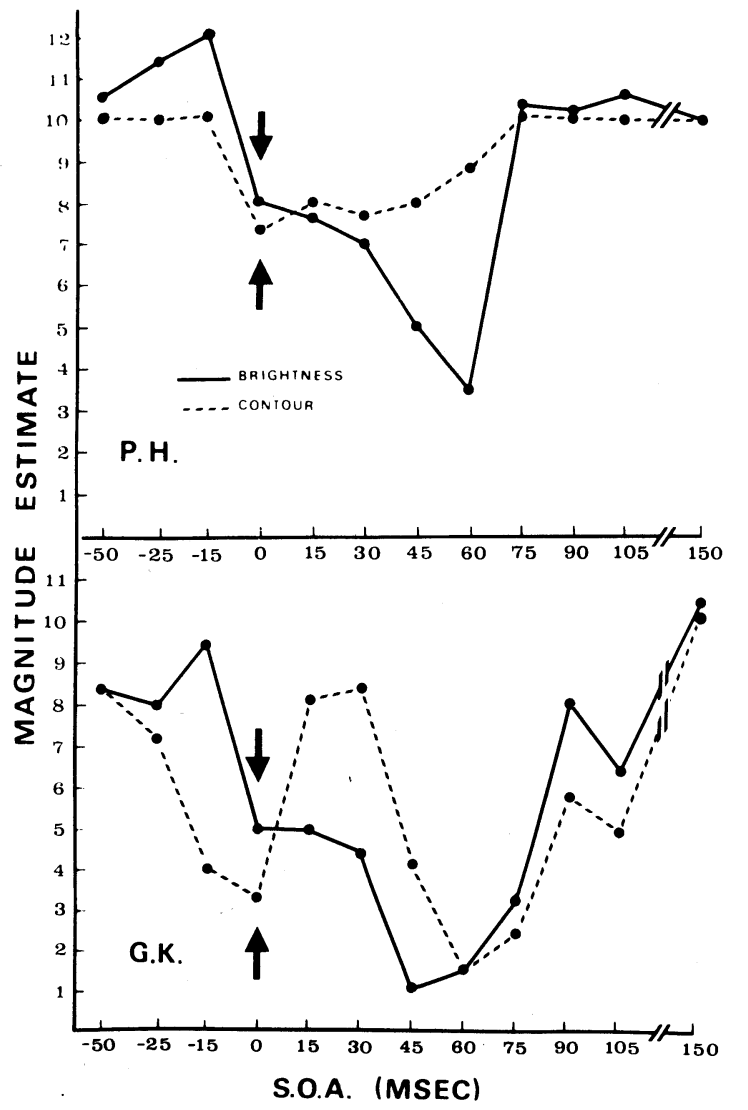

Figure 1. Geometric mean magnitude estimates as a function of stimulus onset asynchrony (SOA) for both observers in the foveal fixation condition. Solid lines are for brightness estimates. Dashed lines are for contour clarity estimates. Arrows indicate the zero SOA.

stimulus conditions, we felt that this procedure maintained an inherent correlation between metacontrast effects on target brightness and clarity.

The main manipulation was the stimulus onset asynchrony (SOA) between the target and mask. Both positive (backwardmasking) and negative (forward-masking) SOAs were employed. The precise SOAs used are listed on the abscissas of Figures 1 and 2. On any given trial, the temporal sequence of events was: 10-sec dark fixation field, 8- or 40-msec target (mask) presentation, SOA, 8- or 40-msec mask (target) presentation, 500-msec interstimulus interval (ISI), 8- or 40-msec standard stimulus presentation, 10-sec dark fixation field. In order to accomplish this, additional timing capability was obtained from Colbourn Instruments logic modules.

In any given experimental session, target brightness and clarity estimates were obtained for a single duration and fixation location. A block of five replications was run at each SOA, and SOAs were randomized within observers.

\section{RESULTS}

Figure 1 presents the data from both observers for the $40-\mathrm{msec}$ duration and foveal fixation conditions. The magnitude estimates are geometric means from the five replications. For the moment, consider only the backward-masking or metacontrast conditions, which are represented by the data to the right of and including a SOA of zero.

At SOAs up to $60 \mathrm{msec}$, the magnitude estimates of target brightness and clarity for observer P.H. (upper graph) are negatively correlated. That is, although the contour estimates reflect increasing clarity, the brightness estimates show a reduction along this dimension, as a function of SOA. Beyond a SOA of $60 \mathrm{msec}$, the curves converge and reflect little or no masking.

The data from observer G.K. (lower graph) present a similar picture. Up to a SOA of $30 \mathrm{msec}$, the clarity and brightness estimates are again negatively correlated. Beyond a SOA of $30 \mathrm{msec}$, however, this observer continued to show a masking effect, with the clarity and brightness estimates exhibiting a positive correlation.

The point that target brightness and clarity estimates move in opposite directions at short SOAs and in the same direction at long SOAs is again illustrated in Figure 2. This figure presents data collected with peripheral fixation and has the same format as Figure 1 except that an 8-msec duration condition has been added. Regardless of duration, observer P.H. again shows the negative correlation between the clarity and brightness estimates up to a SOA of $60 \mathrm{msec}$. Beyond $60 \mathrm{msec}$, the positive correlation can be observed in the data. In fact, note that when the 40-msec duration clarity estimates go down at a SOA of $75 \mathrm{msec}$, the 40-msec duration brightness estimates stay down. The

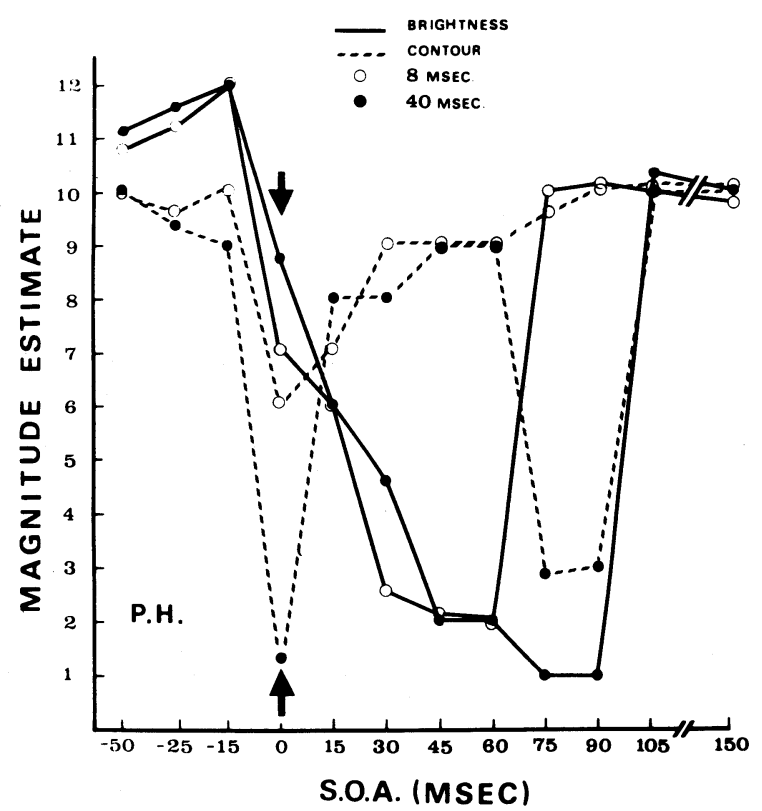

Figure 2. Geometric mean magnitude estimates as a function of stimulus onset asynchrony (SOA) for observer P.H. in the peripheral fixation condition. Solid lines are for brightness estimates. Dashed lines are for contour clarity estimates. Solid circles are for target and mask durations of $40 \mathrm{msec}$. Open circles are for target and mask durations of $8 \mathrm{msec}$. Arrows indicate the zero SOA. 
two functions finally move up together at a SOA of $105 \mathrm{msec}$. The 8-msec duration data show no second minimum, and the brightness estimates join and follow the clarity estimates at a SOA of $75 \mathrm{msec}$.

Another way of demonstrating the negative correlation at low SOAs is to compare the estimates across durations. At a SOA of zero, for example, there was more contour masking when the target and mask were exposed for 40 rather than $8 \mathrm{msec}$. Yet the target presented for $40 \mathrm{msec}$ was judged to be brighter than the same target presented for $8 \mathrm{msec}$.

An ancillary point involves the greater contourmasking effect at target and mask durations of 40 rather than $8 \mathrm{msec}$. This finding is a bit counterintuitive, since it seems less likely that a target presented for a longer period of time (or at a higher energy level) would be interfered with by a mask than would be a target presented for a shorter duration. This finding, for a SOA of zero, has already been reported (Brussell \& Favreau, 1977). In fact, the data in Figure 2 extend this previously reported finding in that more masking at longer target durations was also obtained at longer SOAs (i.e., the second minimum is only observed in the 40 -msec duration data).

\section{DISCUSSION}

The most interesting finding is the negative correlation between target brightness and clarity observed at short SOAs and the lack of it at longer SOAs. One way of beginning to make sense of this result is to explore the implications of different perceptual experiences at different SOAs. At short SOAs, the target and mask should be integrated such that the target is seen against a background of its higher luminance mask. At long SOAs, however, it would be expected that the target and mask would be seen as presented separately in time. That is, the target should be seen against a black background. If, as it is generally agreed, metacontrast is a contour phenomenon (e.g., Weisstein, Ozog, \& Szoc, 1975), and brightness, especially of stimuli larger than $30 \mathrm{~min}$ in diameter, depends heavily upon the processing of information at the edges (e.g., Brussell, Adkins, \& Stober, 1977), then one might expect contour degradation via metacontrast to result in a move of the brightness of the target toward that of its background. It is known that this is true of steady-state stimuli whose edges are optically degraded (e.g., Thomas \& Kovar, 1965), and we can think of no reason why this should not occur with flashed stimuli whose edges are neurally degraded.

Hence, at short SOAs, the greater the metacontrast effect, the more the brightness of the target should move toward that of its higher luminance surround (i.e., become brighter). At longer SOAs, the greater the metacontrast effect, the more the brightness of the target should move toward its lower luminance surround (i.e., become less bright).

On the surface, at least, this type of perceptual description is not incompatible with the recently proposed "sustainedtransient" theories of metacontrast (Breitmeyer \& Ganz, 1976; Weisstein et al., 1975). It simply needs to be assumed that metacontrast involves the inhibition of sustained channels that carry edge information, and that the brightness of the target (which is dependent upon sustained activity) will move toward that of its background with increased inhibition of sustained cells. At long SOAs, it would be the fast transient activity from the mask that inhibits the slow sustained response to the target.
At short SOAs, one can appeal to sustained activity from the mask to inhibit the sustained activity from the target. In fact, this type of explanation might even account for why the second minimum was more readily observed when the stimuli were presented peripherally. That is, the ratio of transient to sustained cells increases with increasing distance from the fovea (Cleland, Levick, \& Sanderson, 1973). One can even begin to work on the increased masking effect at longer durations by examining whether there are differential rates of change within and between populations of sustained and transient cells as a function of increased duration (or energy).

However, the main problem facing both our perceptual description and our very brief attempt to incorporate these data under the "sustained-transient" umbrella involves the effects that were observed in the forward-masking or paracontrast conditions (i.e., data to the left of SOA $=0$ ). We have reliably observed in all the data we have collected (only some of which are presented here) that target brightness and clarity vary together when the mask is presented before the target. Our perceptual description, which depends upon the target and mask being seen simultaneously, would suggest a brighter target with more contour masking at all SOAs around zero, including those in the paracontrast conditions (i.e., a negative correlation).

Second, the data indicate that in the forward-masking conditions, there were reports of the target's being seen as brighter than the standard. This enhancement, or contrast-reversal effect, has puzzled theorists since it was first reported (Werner, 1935) and, in fact, has been ignored by most. A complete description and account of our data has to include the differences between the paracontrast and metacontrast effects. Whether the "sustained-transient" theories, which have elegantly explained much of the metacontrast data, can provide a complete explanation remains to be seen.

\section{REFERENCES}

AlPERn, M. Metacontrast. Journal of the Optical Society of America, 1953, 43, 648-657.

AlPERN, M. Rod-cone independence in the after-flash effect. Journal of Physiology, London, 1965, 176, 462-472.

Alpern, M., \& Rushton, W. A. The specificity of the cone interaction in the after-flash effect. Journal of Physiology, London, 1965, 176, 473-482.

BREITMEYER, B. G., \& GANz, L. Implications of sustained and transient channels for theories of visual pattern masking, saccadic suppression and information processing. Psychological Review, 1976, 83, 1-36.

Brussell, E. M., Adxins, J. A., \& Stober, S. R. Increment thresholds, luminance, and brightness. Journal of the Optical Society of America, 1977, 67, 1354-1356.

Brussell, E. M., \& FaVReau, O. E. Backward pattern masking can vary as a nonmonotonic function of target duration: On the influence of intratarget metacontrast. Journal of Experimental Psychology: Human Perception and Performance, 1977, 3, 461-472.

Cleland, B. G., Levick, W. R., \& Sanderson, K. J. Properties of sustained and transient ganglion cells in the cat retina. Journal of Physiology, London, 1973, 228, 649-680.

FEHRER, E. Effect of stimulus similarity on retroactive masking. Journal of Experimental Psychology, 1966, 71, 612-615.

GROWNEY, R. The function of contour in metacontrast. Vision Research, 1976, 16, 253-261.

Kolers, P. A. Intensity and contour effects in visual masking. Vision Research, 1962, 2, 277-294.

Matteson, H. H. Effects of surround size and luminance on metacontrast. Journal of the Optical Society of America, 1969, 59, 1461-1468. 
Stew art, A. L., \& Purcell, D. G. U-shaped masking functions in visual backward masking: Effects of target configuration and retinal position. Perception \& Psychophysics, 1970, 7, 253-256.

Thomas, J. P., \& Kovar, C. W. The effect of contour sharpness on perceived brightness. Vision Research, 1965, 5, 559-564.

Weisstein, N. W-shaped and U-shaped functions obtained for monoptic and dichoptic disk-disk masking. Perception \& Psychophysics, 1971, 9, 275-278.
Weisstein, N., \& HABER, R. N. A U-shaped backward masking function in vision. Psychonomic Science, 1965, 2, 75-76.

Weisstein, N., Ozog, G., \& Szoc, R. A comparison and elaboration of two models of metacontrast. Psychological Review, 1975, 82, 325-343.

WERNER, H. Studies in contour: I. Qualitative analyses. American Journal of Psychology, 1935, 47, 40-64.

(Received for publication August 28, 1978.) 